\title{
Research on Relationship Between Rural Residents' Income and Electricity Consumption Features
}

\author{
Zili Huang ${ }^{\dagger}$ \\ Business School \\ China University of Political \\ Science and Law, Beijing 102249, \\ China, hzl163yx@163.com
}

\author{
Daimeng Huang \\ Business School \\ China University of Political \\ Science and Law, Beijing 102249, \\ China, autumn970912@sina.com
}

\author{
Kun Guo \\ School of Economics \& \\ Management \\ University of Chinese Academy \\ of Sciences, Beijing 100190, China, \\ guokun@ucas.ac.cn
}

\begin{abstract}
Although China's economy has rapidly increased these years, there still exists an imbalance between developments in different regions. The income of some rural areas is still significantly below the international average level. In order to seek measures to promote rural residents' income growth, this paper used the panel data model to explore the industrial electricity big data considering its timeliness and accuracy, seeking the correlation between electricity consumption and economic development. The study found that the relationship between net income and electricity consumption is strong and could be depicted properly by the panel data model. The study also found that in most poor provinces in China, the income of rural residents was significantly positively correlated with agricultural development, business development and household electricity consumption, however, it was negatively correlated with industrial development. These features provide guidance for policy implementation by government. In addition, the prediction accuracy of the panel model is better than most of machine learning models, due to consideration of the tendency of macroeconomic variables over time.
\end{abstract}

\section{KEYWORDS}

Electricity consumption, Panel data analysis, Per capita net income

\section{ACM Reference format:}

Zili Huang, Daimeng Huang and Kun Guo. 2019. Research on Relationship Between Rural Residents' Income and Electricity Consumption Features. In Proceedings of WI '19: IEEE/WIC/ACM International Conference on Web Intelligence (WI '19 Companion), October 14-17, 2019, Thessaloniki, Greece. ACM, New York, NY, USA, 8 pages. https://doi.org/10.1145/3358695.3360935Introduction

Permission to make digital or hard copies of all or part of this work for personal or classroom use is granted without fee provided that copies are not made or distributed for profit or commercial advantage and that copies bear this notice and the full citation on the first page. Copyrights for components of this work owned by others than ACM must be honored. Abstracting with credit is permitted. To copy otherwise, or republish, to post on servers or to redistribute to lists, requires prior specific permission and/or a fee. Request permissions from permissions@acm.org.

WI '19 Companion, October 14-17, 2019, Thessaloniki, Greece

(c) 2019 Association for Computing Machinery.

ACM ISBN 978-1-4503-6988-6/19/10...\$15.00

https://doi.org/10.1145/3358695.3360935
The economy of China has made remarkable achievements today. China's total economic output has leaped to second place in the world, contributing more than $30 \%$ of the world's economic growth. The urbanization rate of China climbs up to $60 \%$. Space exploration of Tianyan, moon exploration of Change, and sea exploration of Jiaolong have made foreign media exclaimed that "the scientific revolution is taking place in China". However, as the largest developing country in the world, China still has many problems as follows. There still exist problems like a large population base and per capita GDP being in the middle level of the world. There are more than 43 million people eager to get rid of poverty. The gap between urban and rural areas still exists, and so does it between the east and the west. Social contradictions and problems are intertwined, with shortcomings in the field of people's livelihood.

In order to solve these problems, the No. 1 Document of the Central Committee in 2015 pointed out that "emphasizing the basic position of agriculture, improving the conditions for agricultural production", "developing the 'leading economy', cultivating the agricultural market", "developing the order agriculture and reducing the risk of structural adjustment”, and "actively transferring surplus labor and increasing farmers income" were effective solutions ${ }^{1}$. However, the documentation lacks practical guidance and quantitative guidelines. Moreover, the traditional economic surveys and statistical data are not guaranteed in time due to layer-by-layer accounting and reporting. Meanwhile, because of the large number of human operations, the accuracy and objectivity of their statistics are unreliable.

To solve the above problems, electrical big data could be applied to the analysis. The accumulation of big data resources and the development of technology provide an important foundation for accurate poverty alleviation. Many schoolers, such as Boufateh (2012) and Marinaș et al (2018), reported that residents' energy consumption, especially electricity consumption, is significantly correlated with household income. Electricity consumption is an important part of the Keqiang index due to its characterization of economic development. Electricity data has the characteristics of real-time and high

\footnotetext{
Corresponding Author

1 Source: Peoples website.

http://gs.people.com.cn/n/2015/0205/c360943-23801739.html
} 
precision, which provide timely and accurate information for the precise poverty alleviation policies.

Therefore, this paper will try to explore ways to improve farmers' income level based on the collection and analysis of electricity consumption data in six provinces, that is A, B, C, D, E, and $\mathrm{F}$ province.

\section{Literature Review}

Energy, as a significant component of economic development, is an important tool for social and economic advancement. The relationship between energy consumption and economic growth is an important topic in the fields of economy, economic development, and energy policy.

Shakeel (2014) and Mahalik (2014) all discussed the relationship between overall energy consumption and economic growth. Both of the scholars choose data related to GDP as an indicator to measure the level of economic development. According to Shakeel's research, there is a two-way causal relationship between energy consumption and economic development in both short and long term, so the shortage of energy supply will hinder economic growth. Mahalik's article indicates that energy use will contribute to economic development, but it is negatively correlated with financial development.

Some scholars subdivided energy consumption into gas, oil, electricity, and coal, in order to study their different effects on economic growth. Khan (2008) and Faridi (2013) had analyzed the impact of energy consumption on economic growth in both short and long term. Khan believes that electricity consumption is positively correlated with per capita real income in the short term, and the elasticity difference of energy consumption will have great impact on income level and related policies. Faridi reckoned that short-term power shortage will damage economic growth, and in the long run, gas and oil are the key to sustainable economic growth. Joyeux (2011) and Ahmad (2014) studied the impact of different types of energy consumption on economic development by selecting panel data from different countries. The analysis indicates that there is a significant positive correlation between economic growth and electricity consumption. Furthermore, according to Ahmad, the sustainable supply of all kinds of energy, especially electricity, has a significant impact on economic growth.

Besides, many scholars studied the causation relationship between power consumption and other variables. Some scholars have carried out a detailed analysis of the relationship between electricity consumption and economic growth indicators. Tang (2012) showed there exists two-way causal relationship between electricity consumption and economic growth. Similarly, Kirikkaleli et al (2018) and other scholars believed that there is a positive relationship between electricity consumption and economic growth, while the causal relationship between electricity consumption and economic development is one way. Liddle (2013) emphasized the impact of urbanization on economic development. Furthermore, urbanization, electricity consumption and economic growth indicators are interdependent and have correlated effects. In addition, Khandker et al (2012) and Kumar (2014) also discussed electricity consumption and welfare issues. Scholars, such as Khandker, emphasized the positive impact of electricity supply on family welfare, while Kumar discussed the economic welfare of each region by analyzing electricity consumption and per capita income of residents.

To conclude, from these papers we can find that there is probably a relationship between electricity consumption and income level, and it is reasonable to research how to increase income by analyzing the electricity data.

\section{Data}

\subsection{Data Selection}

This paper selects electricity consumption data of 151 counties in 6 provinces provided by State Grid Corporation of China from 2008 to 2018 for analysis, including 136 poverty-stricken counties and 15 poverty-free counties. Per capita net income of rural residents $(y)$ are also collected for model analysis ${ }^{2}$.

In terms of electricity consumption data, this paper uses the industrial electricity consumption, agricultural electricity consumption, commercial electricity consumption, and residential electricity consumption as the main analysis targets. Among them, industry, agriculture, and commerce are important industries supporting economic development, so their electricity consumption accurately describes the development of macroeconomics. The electricity consumption of residents is an important indicator of people's livelihood, and it is also an important measure of residents' living standards. Therefore, the analysis of the above indicators can effectively and comprehensively track the real situation of the macroeconomic environment, thus providing guidance for China's precise poverty alleviation policy.

\subsection{Data Processing}

To eliminate scale effect, this paper divides industrial electricity consumption, agricultural electricity consumption, and commercial electricity consumption by total electricity consumption, and obtains industrial proportion $\left(x_{1}\right)$, agricultural proportion $\left(x_{2}\right)$, and commercial proportion $\left(x_{3}\right)$. These factors are used to portray the industrial structure. In fact, different industrial structures in the county lead to different economic development modes, while different development modes contribute to differences in residents' income. Therefore, the above measures are consistent with the poverty alleviation objectives of this paper.

For residential electricity consumption and total electricity consumption, this paper divides it by the number of households to get residential electricity consumption per household $\left(x_{4}\right)$ and total electricity consumption per household $(x)$.

In addition, this paper also calculates the growth rate of industrial, agricultural, commercial, residential and total

\footnotetext{
2 Data source: National and Provincial statistical yearbooks.
} 
Research on Relationship Between Rural Residents' Income and Electricity Consumption Features

electricity consumption, and that of rural residents' income to describe the dynamic changes of various indicators, all of which expressed by the suffix $(r t)$.

Although the net income and electricity consumption of households is significantly different and fluctuate widely in different provinces, the growth rate indicators are relatively stable, which are conducive to subsequent analysis and modeling process.

\section{Correlation Analysis}

\subsection{Analysis of Aggregation Data of Six Provinces}

First, using data from the entire sample pool as input, including 658 samples. Pearson correlation analysis is performed by using SPSS. The results are as shown in table 1:

Table 1: Correlation analysis of original variables in all provinces.

\begin{tabular}{ccccccc}
\hline & $\mathrm{Y}$ & $\mathrm{X} 1$ & $\mathrm{X} 2$ & $\mathrm{X} 3$ & $\mathrm{X} 4$ & $\mathrm{X}$ \\
\hline $\mathrm{Y}$ & $\mathbf{1}$ & & & & & \\
$\mathrm{X} 1$ & $-.086^{*}$ & 1 & & & & \\
$\mathrm{X} 2$ & $-.297^{*}$ & & & & & \\
$\mathrm{X} 3$ &. $.217^{* *}$ & 1 & & & \\
$\mathrm{X} 4$ &. $\mathbf{2 6 6 ^ { * * }}$ & $-.430^{* *}$ & $-.275^{* *}$ & 1 & & \\
$\mathrm{X}$ & $-.260^{* *}$ & $-.119^{* *}$ & .009 & 1 & \\
\hline & $.677^{* *}$ & $-.131^{* *}$ & $-.339^{* *}$ & $.270^{* *}$ & 1 \\
\hline
\end{tabular}

According to table 1, this paper finds that there are significant correlations between the dependent variable and all other five variables (1 star or 2 stars). Among them, per capita net income of rural residents $(y)$ is positively correlated with commercial proportion $\left(x_{3}\right)$ and residential electricity consumption $\left(x_{4}\right)$, while negatively correlated with industrial proportion $\left(x_{1}\right)$, agricultural proportion $\left(x_{2}\right)$, and total electricity consumption per household $(x)$.

Next, this paper conducts the correlation analysis between the growth rate of different variables as follows.

Through the correlation analysis of incomes' growth rate in table 2, it can be found that the correlations between per capita net income of rural residents growth rate and other variables are not obvious generally; but in the panel data model, using provincial dummy variables and time fixed effects to eliminate irrelevant features can reflect the implicit correlation between growth rate and other variables. Net income has a significant negative correlation with industrial growth rate (that is, the correlation coefficient between $y$ and $x_{1} r t$ is -0.113), which will be analyzed in later part.
WI '19 Companion, October 14-17, 2019, Thessaloniki, Greece

Table 2: Correlation analysis result of all variables in all provinces (including increase rate).

\begin{tabular}{|c|c|c|c|c|c|c|}
\hline & $\mathbf{Y}$ & YRT & $\mathrm{X} 1$ & X1RT & X2 & $\mathrm{X} 2 \mathrm{RT}$ \\
\hline $\mathrm{Y}$ & 1 & & & & & \\
\hline YRT & -.067 & 1 & & & & \\
\hline $\mathrm{X} 1$ & $-.111^{*}$ & $.091^{*}$ & 1 & & & \\
\hline X1RT & $-.13^{* *}$ & .013 & .015 & 1 & & \\
\hline X2 & $-.34^{* *}$ & .066 & $-.21^{* *}$ & $.112^{*}$ & 1 & \\
\hline $\mathrm{X} 2 \mathrm{RT}$ & $.119^{*}$ & .001 & -.030 & .022 & $-.096^{*}$ & 1 \\
\hline $\mathrm{X} 3$ & $.22^{* *}$ & .014 & $-.45^{* *}$ & $-.094^{*}$ & $-.32^{* *}$ & $.091^{*}$ \\
\hline X3RT & -.062 & .074 & -.067 & $.24^{* *}$ & -.041 & $-.113^{*}$ \\
\hline $\mathrm{X} 4$ & $.44^{* *}$ & -.007 & .051 & $-.095^{*}$ & $-.34^{* *}$ & $.25^{* *}$ \\
\hline X4RT & -.041 & -.027 & .015 & $.15^{* *}$ & .031 & -.004 \\
\hline $\mathrm{X}$ & $-.13^{* *}$ & .065 & $.74^{* *}$ & -0.018 & $-.16^{* *}$ & .031 \\
\hline XRT & $\begin{array}{c}-0.04 \\
8 \\
\end{array}$ & -.015 & -.038 & $.46^{* *}$ & $.092^{*}$ & .053 \\
\hline $\begin{array}{c}\text { conti } \\
\text { nue }\end{array}$ & X3 & X3RT & $\mathrm{X} 4$ & X4RT & $\mathrm{X}$ & XRT \\
\hline Y & & & & & & \\
\hline YRT & & & & & & \\
\hline $\mathrm{X} 1$ & & & & & & \\
\hline $\mathrm{X} 1 \mathrm{RT}$ & & & & & & \\
\hline $\mathrm{X} 2$ & & & & & & \\
\hline X2RT & & & & & & \\
\hline $\mathrm{X} 3$ & 1 & & & & & \\
\hline X3RT & $.18^{* *}$ & 1 & & & & \\
\hline $\mathrm{X} 4$ & $.21^{* *}$ & .077 & 1 & & & \\
\hline X4RT & .034 & $.26^{* *}$ & $.14^{* *}$ & 1 & & \\
\hline $\mathrm{X}$ & $-.38^{* *}$ & $-.115^{*}$ & .020 & .087 & 1 & \\
\hline XRT & .023 & $.20^{* *}$ & .075 & $.59^{* *}$ & -.008 & 1 \\
\hline
\end{tabular}

\subsection{Provincial Data Analysis}

Since different provinces usually have unique development features, poverty alleviation work should be tailored to local conditions, and appropriate assistance should be provided for the industrial characteristics of each province. Therefore, the correlation analysis of the data of the six provinces uniquely is carried out. The results are as shown in table 3 to table 8: 
Table 3: Correlation analysis result of six provinces separately A Province.

\begin{tabular}{ccccccc}
\hline Prv A & Y & X1 & X2 & X3 & X4 & X \\
\hline Y & $\mathbf{1}$ & & & & & \\
X1 & -.069 & 1 & & & & \\
X2 & -.112 & .109 & 1 & & & \\
X3 & $\mathbf{. 0 2 1}^{*}$ & $-.302^{* *}$ & $-.556^{* *}$ & 1 & & \\
X4 &.$- .700^{*}$ & .069 & .112 & .047 & 1 & \\
X &.$- \mathbf{1 8 9}^{*}$ & $.404^{* *}$ & .147 & $-.273^{* *}$ & $.337^{* *}$ & 1 \\
\hline
\end{tabular}

Table 4: B Province.

\begin{tabular}{ccccccc}
\hline Prv B & Y & X1 & X2 & X3 & X4 & X \\
\hline Y & $\mathbf{1}$ & & & & & \\
X1 &.$- .162^{*}$ & 1 & & & & \\
X2 & $\mathbf{0 . 0 1 9}$ & $-.598^{* *}$ & 1 & & & \\
X3 & $.223^{* *}$ & $-.495^{* *}$ & -0.125 & 1 & & \\
X4 &. $\mathbf{3 3 7}$ & $.243^{* *}$ & $-.374^{* *}$ & -0.115 & 1 & \\
X & $\mathbf{- 0 . 0 1 7}$ & $.833^{* *}$ & $-.464^{* *}$ & $-.514^{* *}$ & $.471^{* *}$ & 1 \\
\hline
\end{tabular}

Table 5: C Province.

\begin{tabular}{ccccccc}
\hline Prv C & Y & X1 & X2 & X3 & X4 & X \\
\hline Y & $\mathbf{1}$ & & & & & \\
X1 & $\begin{array}{c}-.244^{*} \\
*\end{array}$ & 1 & & & & \\
X2 & $\mathbf{0 . 0 2 6}$ & $-.310^{* *}$ & 1 & & & \\
X3 & $\mathbf{0 . 0 1 9}$ & $-.416^{* *}$ & 0.02 & 1 & & \\
X4 & $-\mathbf{0 . 1 0 3}^{*}$ & $.751^{* *}$ & $-.253^{* *}$ & $-.337^{* *}$ & 1 & \\
X & $\mathbf{. 5 0 5}^{* *}$ & -0.023 & 0.025 & $.205^{*}$ & 0.077 & 1 \\
\hline
\end{tabular}

Table 6: D Province.

\begin{tabular}{ccccccc}
\hline Prv D & Y & X1 & X2 & X3 & X4 & X \\
\hline Y & $\mathbf{1}$ & & & & & \\
X1 & $\mathbf{- 0 . 0 9 5}$ & 1 & & & & \\
X2 &. $\mathbf{4 4 9 * *}$ & 0.011 & 1 & & & \\
X3 & $\mathbf{0 . 1 2 7}$ & $-.715^{* *}$ & -0.159 & 1 & & \\
X4 & $\mathbf{0 . 0 7 8}$ & $.673^{* *}$ & -0.08 & $-.317^{* *}$ & 1 & \\
X &. $\mathbf{3 2 2}^{* *}$ & -0.161 & 0.061 & $.288^{* *}$ & $.501^{* *}$ & 1 \\
\hline
\end{tabular}

Through the correlation analysis of the six provinces, this paper found that in most provinces, per capita net income of rural residents is significantly related to residential electricity consumption. The correlations between per capita net income of rural residents and industrial proportion, agricultural proportion, and commercial proportion vary from province to province, which indicates the unique economic structure in different provinces.

Table 7: E Province.

\begin{tabular}{ccccccc}
\hline Prv E & Y & X1 & X2 & X3 & X4 & X \\
\hline Y & $\mathbf{1}$ & & & & & \\
X1 & $\mathbf{- 0 . 0 5 9}$ & 1 & & & & \\
X2 & $\mathbf{- 0 . 0 1 1}$ & $-.328^{* *}$ & 1 & & & \\
X3 & $\mathbf{0 . 0 9 4}$ & $-.338^{* *}$ & -0.182 & 1 & & \\
X4 & $\mathbf{. 6 4}^{*}$ & $.540^{* *}$ & $-.353^{* *}$ & -0.13 & 1 & \\
X & $\mathbf{. 3 9 1}^{* *}$ & 0.192 & -0.228 & 0.003 & $.703^{* *}$ & 1 \\
\hline
\end{tabular}

Table 8: F Province.

\begin{tabular}{ccccccc}
\hline Prv F & Y & X1 & X2 & X3 & X4 & X \\
\hline Y & $\mathbf{1}$ & & & & & \\
X1 & $\mathbf{- 0 . 2 2 7}$ & 1 & & & & \\
X2 & $\mathbf{. 5 4 9}^{* *}$ & -0.295 & 1 & & & \\
X3 & $\mathbf{0 . 2 2 2}$ & -0.218 & 0.17 & 1 & & \\
X4 & $\mathbf{- 0 . 0 5 3}$ & $.547^{* *}$ & 0.019 & -0.168 & 1 & \\
X & $\mathbf{0 . 0 8 3}$ & $.502^{*}$ & 0.117 & -0.014 & $.959^{* *}$ & 1 \\
\hline
\end{tabular}

Detailly, the net income of D and F is significantly positively correlated with agricultural proportion, while in other provinces, the relationships are not so significant. To illustrate, D and F, as the western provinces of China, where the main economic pillars are still dominated by agriculture, are not particularly developed in industry and commerce. Therefore, when the agricultural electricity consumption rises, the economic condition can be significantly improved, thus raising the per capita net income of rural residences.

In $\mathrm{B}$, net income is significantly positively correlated with commercial proportion, which proves that the economic structure transformation is successful, and the tertiary industry obviously drives the economic growth. Hence, promoting the construction of modern service industry is an important way to promote rural residents' income. In C, there is a significantly negative correlation between net income and industrial proportion. In addition, in $\mathrm{A}$ and $\mathrm{B}$, there is also certain negative correlation between net income and industrial proportion but is not significant enough. Moreover, there is no significant correlation between net income and all proportion of electricity consumption in E.

Finally, except for B, the relationships between net income and total energy consumption are positive in all provinces, which means that when total energy consumption increases, the residents' net income will increase too. However, the residential electricity consumption is positively related to net income in 
Research on Relationship Between Rural Residents' Income and Electricity Consumption Features

some provinces, but negatively related to other provinces, which adds the complexity to relative analysis.

Generally speaking, in these six provinces, the industrial proportion is negative related to per capita rural residents' net income, while the agricultural and business proportion are positive related to it. This indicates that under the background of overcapacity and supply-side reform in China these years, the backward industrial production capacity should be reduced. Accelerating the transformation of industrial structure and promoting the construction of the tertiary industry is the core of boosting economic development and increasing residents' income.

\section{Panel Data Analysis}

Through correlation analysis above, measures to increase the net income of rural residents can be initially portrayed. However, due to the uncontrolled time trend of static correlation, for instance, the net income of residents and the total electricity consumption have a same year-on-year growth trend, the correlation coefficient of the two factors is often high, while actually there may be no substantial correlation. Therefore, this paper puts the data into the panel data model to conduct a regression analysis. Through controlling the variables, this model tries to describe the relationship between net income and electricity consumption characteristics more accurately.

In this paper, net income and net income growth rates are used as dependent variables. By putting different independent variables repeatedly, the model with the best fitting result is selected. The results are shown in table 9:

According to model (1), per capita net income of rural residents in F Province is the highest one, while A Province is the lowest one. Net income increases year by year. In addition, the average income of poverty-free counties is 476.46 yuan higher than that of poverty-stricken counties. The $\mathrm{R}$ square (0.859) and the adjusted R square (0.855) of model (1) are both large, indicating that the model fits the data well.

Model (1) indicates that, with other factors unchanged, per capita net income of rural residents is positively correlated with residential electricity consumption and agricultural proportion.

Model (2) shows that per capita net income of rural residents' growth rate is positively correlated with agricultural growth rate and commercial growth rate. Comparing the net income growth rate of each province, it can be found that the growth rate of net income in F Province is lower than that in other provinces, while the growth rate of E Province with relatively lower per capita income is relatively higher. This finding shows that the poorer provinces usually develop at a higher speed.
WI '19 Companion, October 14-17, 2019, Thessaloniki, Greece

Table 9: The regression result of panel data analysis.

\begin{tabular}{|c|c|c|c|c|c|c|}
\hline & \multicolumn{2}{|c|}{ (1) $\mathrm{Y}$} & \multicolumn{2}{|c|}{ (2) YRT } & \multicolumn{2}{|c|}{ (3) $\mathrm{Y}$} \\
\hline $\begin{array}{c}C \| \\
2008\end{array}$ & $\begin{array}{c}7559^{* * *} \\
(198)\end{array}$ & -3003.97 & $\begin{array}{l}0.068^{*} \\
(0.008)\end{array}$ & ---- & $\begin{array}{c}7899^{* * *} \\
(228)\end{array}$ & ---- \\
\hline $\begin{array}{cc}\mathrm{X} 2 & \| \\
2009\end{array}$ & $\begin{array}{c}2641^{* * *} \\
(460)\end{array}$ & -2762.29 & ---- & -0.05255 & $\begin{array}{c}2898^{* * *} \\
(515)\end{array}$ & -2990.52 \\
\hline $\begin{array}{cc}\mathrm{X} 4 & \| \\
2010\end{array}$ & $\begin{array}{c}0.293^{* * *} \\
(0.084)\end{array}$ & -2486.81 & ---- & -0.02192 & $\begin{array}{c}1.94 \mathrm{e}-5^{*} \\
(1 \mathrm{e}-6)\end{array}$ & -2689.97 \\
\hline $\begin{array}{l}\text { X1RT } \\
\| 2011\end{array}$ & $\begin{array}{l}---- \\
----\end{array}$ & -1977.27 & ---- & 0.03159 & $\begin{array}{c}-158^{*} \\
(83)\end{array}$ & -2101.52 \\
\hline $\begin{array}{l}\text { X2RT } \\
\| 2012\end{array}$ & $\begin{array}{l}---- \\
----\end{array}$ & -1346.99 & $\begin{array}{l}0.002^{*} \\
(0.001)\end{array}$ & 0.03354 & $\begin{array}{l}---- \\
----\end{array}$ & -1549.00 \\
\hline $\begin{array}{l}\text { X3RT } \\
\| 2013\end{array}$ & ---- & -563.87 & $\begin{array}{l}0.005^{*} \\
(0.003)\end{array}$ & 0.04824 & ---- & -819.80 \\
\hline $\begin{array}{l}\text { D1 \| } \\
2014\end{array}$ & $\begin{array}{c}-3243^{* * *} \\
(208)\end{array}$ & 197.91 & $\begin{array}{c}0.034^{* * *} \\
(0.008)\end{array}$ & 0.01522 & $\begin{array}{c}-3336^{* * *} \\
(260)\end{array}$ & 49.08 \\
\hline $\begin{array}{l}\text { D2 } \| \\
2015\end{array}$ & $\begin{array}{c}-2456 \text { *** } \\
(208)\end{array}$ & 1048.95 & $\begin{array}{c}0.055^{* * *} \\
(0.008)\end{array}$ & 0.00152 & $\begin{array}{c}-2288^{* * *} \\
(245)\end{array}$ & 781.76 \\
\hline $\begin{array}{cc}\text { D3 } & \| \\
2016\end{array}$ & $\begin{array}{c}-652^{* * *} \\
(205)\end{array}$ & 1734.30 & $\begin{array}{c}-0.041^{* * *} \\
(0.008)\end{array}$ & -0.01973 & $\begin{array}{l}-490^{*} \\
(256)\end{array}$ & 1521.37 \\
\hline $\begin{array}{cc}\text { D4 } & \| \\
2017\end{array}$ & $\begin{array}{c}-576^{* * *} \\
(206)\end{array}$ & 2896.71 & $\begin{array}{c}0.037^{* * *} \\
(0.008)\end{array}$ & -0.01040 & $\begin{array}{c}-589^{* *} \\
(271)\end{array}$ & 2615.61 \\
\hline $\begin{array}{c}\text { D5 } \\
\text { D0 } \\
\end{array}$ & $\begin{array}{c}-1402^{* * *} \\
(222)\end{array}$ & $\begin{array}{c}476^{* * *} \\
(120)\end{array}$ & $\begin{array}{c}0.064^{* * *} \\
(0.008)\end{array}$ & ---- & $\begin{array}{c}-1078^{* * *} \\
(267) \\
\end{array}$ & $\begin{array}{c}337^{* * *} \\
(138)\end{array}$ \\
\hline $\mathbf{N}$ & 6 & 88 & 4 & 69 & $\overrightarrow{46}$ & 9 \\
\hline $\mathbf{R}^{2}$. & 0.85 & 9235 & 0.47 & 3260 & $\underline{0.877}$ & 7933 \\
\hline $\begin{array}{c}\text { Adj. } \\
\mathbf{R}^{2}\end{array}$ & 0.85 & 5496 & 0.45 & 5818 & $\underline{0.873}$ & 3332 \\
\hline
\end{tabular}

Note: Left sub column corresponds to the variable in the left side of "||", and right sub column corresponds to the variable in the right side of "|l”.

The result of model (3) is similar to that of model (1). Except for an additional variable "industrial electricity consumption growth rate", the remaining coefficients are in the same directions of influence. With different data and different variables, the model showed highly consistent fitting results, which proved the stability of regression analysis and the predictable correlation between energy consumption and economic growth. In addition, the variables' coefficients in model (3) are also consistent with the correlation analysis in the former part (i.e. industrial energy consumption's growth rate is negatively related with net income).

The negative coefficient of net income and industrial growth rate proves that the growth in industrial sector is somewhat counterproductive to economic growth. Moreover, when the industrial growth rate is added to the model, the fitting accuracy 
is increased by about $2 \%$. The fitting result of model (3) is drawn as follows:

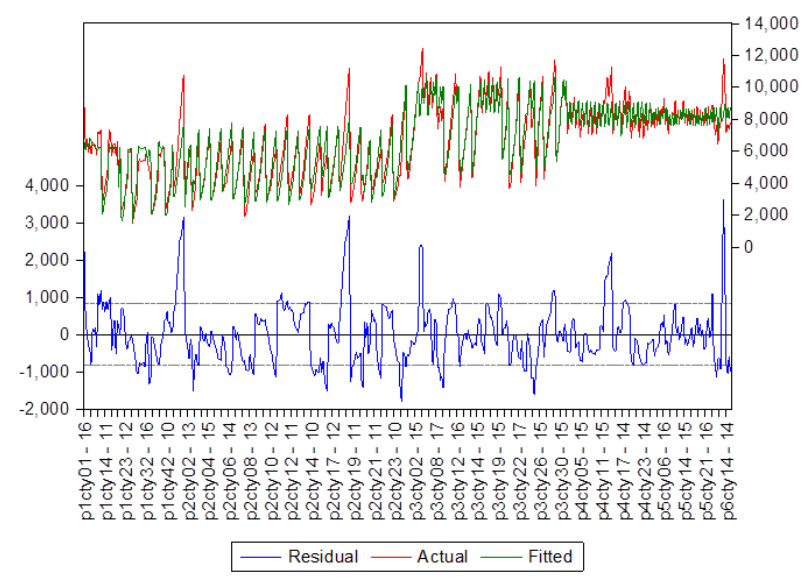

Figure 1: The fitting result of model (3).

As it can be observed from figure 1, in addition to some abnormal data of per capita net income of rural residents, the overall fitting performance is well, and the residual value is also fluctuating around zero. Therefore, the model (3)'s results are ideal and can be chosen as the optimal regression equation for the prediction in later part. The regression equation for the characteristics of electricity consumption and rural net income is:

Per capita net income of rural residents $=7899+1.94 \times 10^{-5}$ $\times$ residential electricity consumption $+2898 \times$ agricultural proportion $-158 \times$ industrial growth rate $+337 \times$ dummy variable of poverty or not + dummy variable of province + dummy variable of time

The equation reveals that increasing the electricity consumption of residents, increasing agricultural proportion, and removing backward industrial production capacity can, to a certain extent, increase the income of rural residents.

\section{Comparison}

Next, to verify the prediction accuracy of panel model, this paper conducted a comparison of it with other machine learning models, such as neural network, support vector machine, and regression tree.

Using $x$ and $x_{1}$ to $x_{4}$ as independent variables, $y$ as dependent variable, randomly selecting $75 \%$ of raw data as the training set, the rest of data as test set, and running different machine learning models. Calculating the goodness of fit $\left(\mathrm{R}^{2}\right)$ and the mean absolute percentage error (MAPE) of different models. The results are as follows.
Table 10: Comparison of different machine learning models.

\begin{tabular}{ccccc}
\hline & BPnetwork & Grnn & Tree & SVM \\
\hline $\mathrm{R}^{2}$ train & 0.243 & 1 & 0.8087 & 0.0961 \\
$\mathrm{R}^{2}$ test & 0.0679 & 0.0632 & 0.1806 & 0.0884 \\
$\mathrm{MAPE}$ & 0.3086 & 0 & 0.1239 & 0.3774 \\
train & 0.3903 & 0.3515 & 0.2931 & 0.3614 \\
MAPE test & &
\end{tabular}

Note: The $\mathrm{R}^{2}$ means the goodness of fitting, the larger is better; and MAPE means the mean absolute percentage error, the smaller is better.

As can be seen from table 10, although the fitting results of training set in generalized regression neural network (Grnn) and regression tree (Tree) are good, none of the fitting results of test set are satisfactory (the values of $\mathrm{R}^{2}$ of test set of all four machine learning models are less than 0.2 ). This reflects the use of machine learning model to predict rural residents' net income may lead to over-fitting, because the data set is too small (only 658 samples in total). Therefore, the fitting results of machine learning models underperform that of panel data model.

To show performances of four machine learning models clearly, the predicted and real values of the dependent variable in training and test set are plotted separately below:
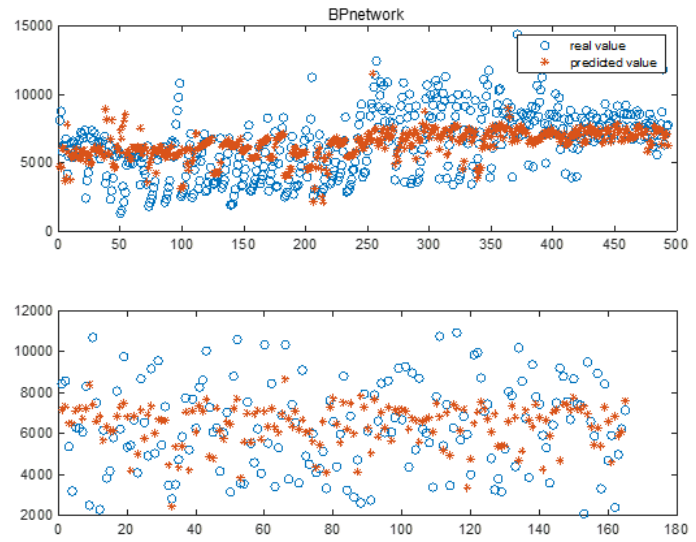

Figure 2: The fitting result of BP neural network. 
Research on Relationship Between Rural Residents' Income and Electricity Consumption Features
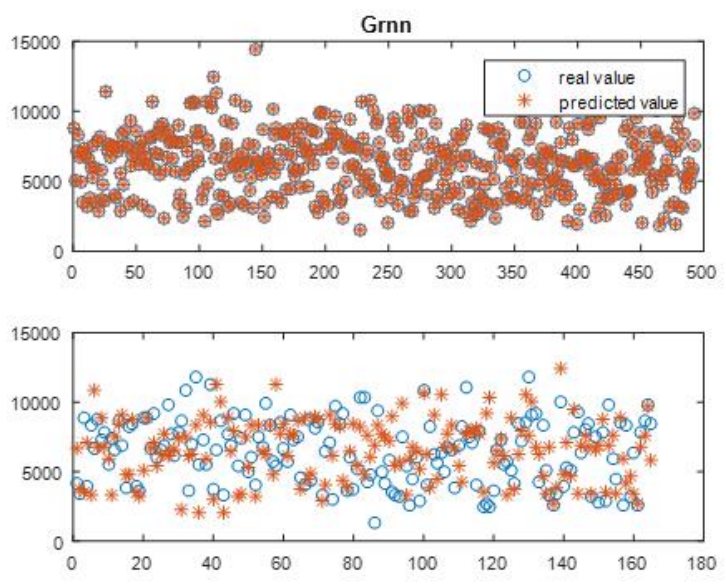

Figure 3: The fitting result of generalized regression neural network.
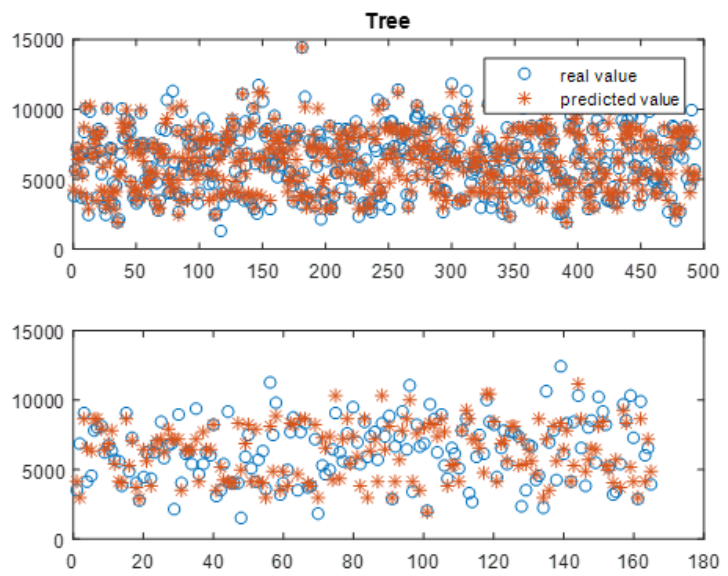

Figure 4: The fitting result of regression tree.
WI '19 Companion, October 14-17, 2019, Thessaloniki, Greece
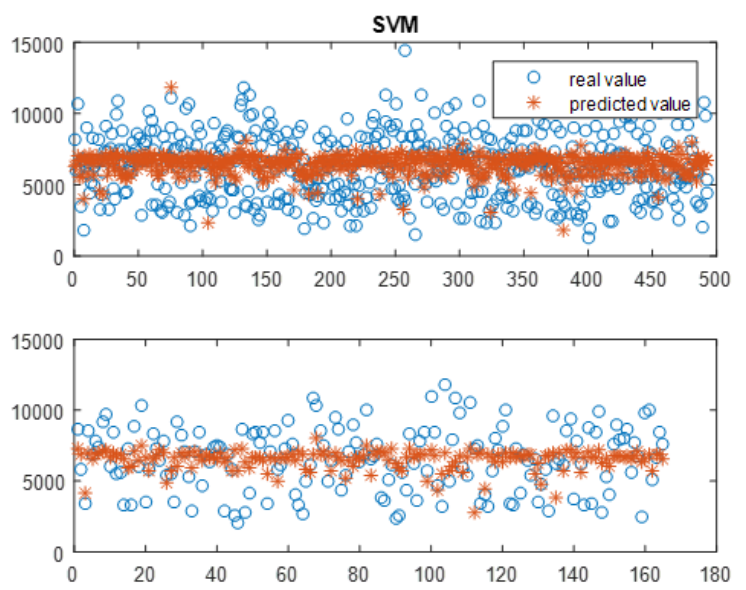

Figure 5: The fitting result of support vector machine.

Obviously, through figure 2 to figure 5 , it can be found that the fitting results in training set of both generalized regression neural network and regression tree models are in a great accuracy, while that in test set are significantly poorer, which means the models are not reliable. Similarly, the other two models don't show ideal fitting performances too.

In a word, due to the small sample pool and the loss of time trend feature of the machine learning models, massive forecasting errors will be derived by them. Hence, compared with other popular models, panel data model is a better model when it comes to predicting net income of rural residents based on electricity consumption data.

\section{Prediction}

Finally, this paper introduces the application of the aforementioned model and taking a prediction of Luanchuan County in C Province as an example. According to the panel regression equation above, drawing agricultural proportion $\left(x_{2}\right)$, residential electricity consumption per household $\left(x_{4}\right)$, industrial electricity consumption growth rate $\left(x_{1} r t\right)$ and per capita net income of rural residents $(y)$ below. 

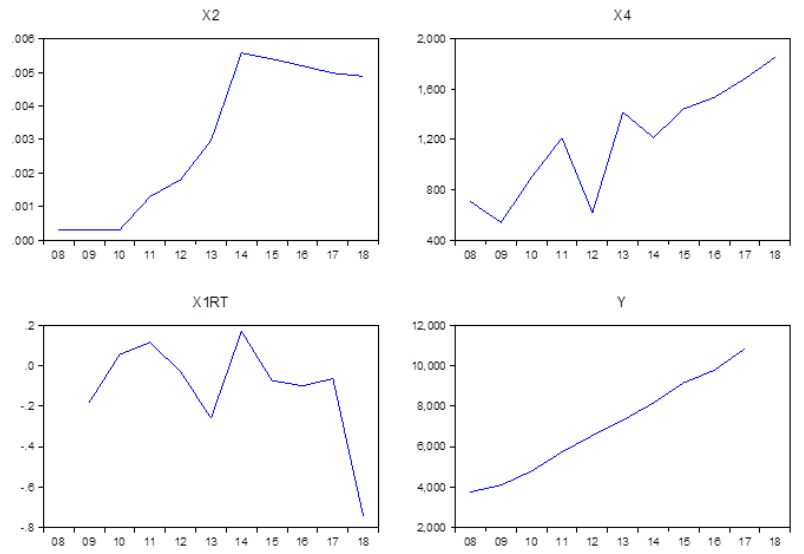

Figure 6: Line chart of independent and dependent variables from 2008 to 2018 .

Due to the lag of economic data, net income data is up to 2017, while other indicators are up to 2018, so this paper forecasts residents' income in 2018 based on these electricity indicators.

As can be seen from figure 6 that the residential electricity consumption of Luanchuan County has increased in recent year, which possibly has positive impact on residents' income in 2018.

Furthermore, the industrial electricity consumption growth rate has plumped in 2018, indicating getting rid of backward productivity successfully, so the net income level should be higher than the normal level, which is consistent with the forecasting result of the panel model shown below.

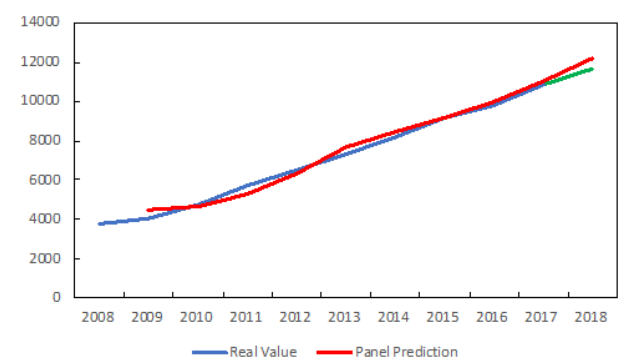

Figure 7: Prediction of rural residents' income in Luanchuan County in 2018 by panel model.

The blue line in figure 7 means the real value of net income from 2008 to 2017, and the green part of the blue line means the prediction of net income in 2018 based on a simple linear growth method. Meanwhile, the red line means prediction of net income by using panel model. Clearly, the net income in 2018 is expected to be higher than the normal (the red line is higher than the green line), which is in line with change in electricity consumption features in that year.

As a result, the panel model can grasp a sudden change of industrial structure in time and improve the prediction accuracy.

\section{Conclusion}

This paper analyzed and predicted the net income of rural residents by using electricity consumption data. It is found that the rural residents' income level can be reasonably predicted by collecting and mining the characteristics of electricity data in various sectors. Through the comparison of different machine learning models, the study found that the panel model could get a better predicted result because it can catch the feather of time trend of macro-economic variables. Finally, it proposed that in order to improve the income level of rural residents, the government can appropriately reduce the backward industrial production capacity, promote the construction of the tertiary industry, and increase residents' daily electricity consumption level, as well as to achieve the ideal result of industrial structure transformation and continuous improvement of residents' quality of life.

\section{ACKNOWLEDGMENTS}

This work is supported by the National Natural Science Foundation of China No. 71501175, the University of Chinese Academy of Sciences, and the Open Project of Key Laboratory of Big Data Mining and Knowledge Management, Chinese Academy of Sciences.

\section{REFERENCES}

Ahmad W. (2014). Energy Sources and Gross Domestic Product: International Evidence. The Pakistan Development Review, 53(4), 477-490.

Boufateh T., Ajmi A., et al (2012). The Dynamic Relationship Between Energy Consumption and Income in Tunisia: A Structural Approach. The Journal of Energy and Development, 38(1), 79-105.

Faridi M., \& Murtaza G. (2013). Disaggregate Energy Consumption, Agricultural Output and Economic Growth in Pakistan. The Pakistan Development Review, 52(4), 493-514.

Joyeux R., \& Ripple R. (2011). Energy Consumption and Real Income: A Panel Cointegration Multi-country Study. The Energy Journal, 32(2), 107-141.

Khan M., \& Ahmad U. (2008). Energy Demand in Pakistan: A Disaggregate Analysis. The Pakistan Development Review,47(4), 437-455.

Khandker S., Barnes D., et al (2012). The Welfare Impacts of Rural Electrification in Bangladesh. The Energy Journal, 33(1), 187-206.

Kirikkaleli D., Sokri A., et al (2018). Panel Cointegration: Long-Run Relationship Between Internet, Electricity Consumption and Economic Growth. Evidence from OECD countries. Investigación Económica, 77 (303), 161-176.

Kumar S. (2014). Convergence in Electricity Consumption in India: A State Level Analysis. Indian Economic Review, 49(2), 173-191.

Liddle B. (2013). The Energy, Economic Growth, Urbanization Nexus Across Development: Evidence from Heterogeneous Panel Estimates Robust to Cross-Sectional Dependence. The Energy Journal, 34(2), 223-244.

Mahalik M., \& Mallick H. (2014). Energy Consumption, Economic Growth and Financial Development: Exploring the Empirical Linkages for India. The Journal of Developing Areas, 48(4), 139-159.

Marinaș M., Dinu M., et al (2018). Renewable Energy Consumption and Economic Growth: Causality Relationship in Central and Eastern European Countries. PloS one, 13(10), 20-29.

Shakeel M., Iqbal M., et al (2014). Energy Consumption, Trade and GDP: A Case Study of South Asian Countries. The Pakistan Development Review, 53(4), 461-476.

Tang C., \& Tan E. (2012). Electricity Consumption and Economic Growth in Portugal: Evidence from a Multivariate Framework Analysis. The Energy Journal, 33(4), 23-48. 